\title{
Failure Mode Prediction of Resistance Spot Welded Quenching and Partitioning Steel
}

\author{
Cheng Luo, ${ }^{1, *}$, and Yansong Zhang, ${ }^{1, *}$ \\ ${ }^{1}$ Shanghai Key-Laboratory of Digital Manufacture for Thin-Walled Structures, Shanghai Jiao Tong University, 200240 Shanghai, P.R. \\ China
}

\begin{abstract}
In recent years, a novel Advanced High-Strength Steels called quenching and partitioning (Q\&P) steel has been applied in the automotive industry because its good combination of strength and ductility. In this study, an experimental setup by adopting digital image correlation (DIC) method was firstly developed to establish the constitutive relationship of fusion zone in the spot welds produced by Q\&P980. Stress-strain relationship extracted from the tensile bar within the fusion zone and compared the results to that of base metal. The fusion zone of Q\&P980 found to have a higher tensile strength and similar elongation compared with base metal. A numerical model established to predict the failure mode of joints generated by Q\&P980 after obtaining the constitutive relationship of fusion zone. The predicted failure mode was in good coherence with the experimental results under the lap-shear test conditions. The developed FE model was proven efficient in tensile strength and failure mode characterization of spot welded specimen. This study could provide solutions to maintain or even improve vehicle crashworthiness of lightweight vehicle structures.
\end{abstract}

\section{Introduction}

The increasing development of automotive industry posed an urgent demand for the lightweight leading to the application of AHSS of body-in-white, such as B pillar, bumper and front rail. AHSS have developed for three generation to meet various requirements of lightweight. The third generation AHSS attracted interests in automotive manufactory currently due to excellent combination of strength and ductility over previous generations. The promising candidate included the Q\&P steel, which is produced with a quenching and partitioning heat treatment process [1]. During the process, the ductility and strength enhanced by the decarburization of martensite and carbon enrichment in the retained austenite [2].Resistance spot welding (RSW) had been widely used in automotive structure assembly with the advantages of low cost, high efficiency and easy auto-mission. For Q\&P steel, RSW was still the first trial to generate favourable joint when applied in automotive industry.

Similar to conventional AHSS, Q\&P steel should be weldability and be able to obtain favourable failure mode of spot welds. FEA model was an efficient method to make investigation on the failure mode and fracture mechanism of spot welds [3-4].Recently, numerous FEA models had been developed to predict and understand the failure mode in various loading conditions, such as tension condition, tensile shear condition and the combination [5-7]. For the tensile shear condition of AHSS, the influence of HAZ softening effect and stress intensity on failure modes were taken into consideration in FEA model $[8,9]$. However, for Q\&P980, retained austenite would turn into martensite in the fusion zone during RSW process. The fidelity of the numerical model required an accurate description of constitutive relationship in fusion zone. The method to demonstrate the material property of fusion zone was still the issue for researches.

Hardness extrapolation method was a conventional method to obtain the constitutive relationship of fusion zone $[10,11]$. Eller et al. established the constitutive relationship of different phases in boron steel and then obtained the true stress-strain curve of fusion zone based on the phase fraction calculated from hardness distribution [12]. However, phase transformation occurred in fusion zone of Q\&P980 during RSW process. The accuracy of hardness extrapolation needed further validation for Q\&P980. The alternative method was to extract the constitutive relationship of fusion zone from tensile specimen assisted with DIC device. Recently, researches applied DIC device to measure the constitutive relationship of fusion zone during tensile tests [13-16]. Tong et al. adopted DIC technique with redesigned miniature to measure the stress-strain curves of fusion zone in DP590 [17]. The miniature required complicated fix device and test procedures resulting in high expenditure. This paper seed to apply DIC device to extract constitutive relationship of fusion zone in resistance spot-welded Q\&P980 with convenience and low expenditure.

Corresponding author: zhangyansong@ @itu.edu.cn 
This paper adopted DIC device to measure the constitutive relationship of fusion zone and subsequently a FEA model established to predict the failure mode of resistance spot welds in Q\&P980. Besides, the microstructure, mechanical performance and failure mode of spot-welds in Q\&P980 discussed in the paper.

\section{Experimental procedure}

\subsection{Materials}

The investigated material was bared quenching and partitioning steel (Q\&P980) with thickness of $2 \mathrm{~mm}$. The chemical composition (in wt. \%) of Q\&P980 considered here were demonstrated in Table 1. Note that the addition of Si was to delay the formation of carbide and increase the hardenability of austenite during partitioning process. The ultimate tensile strength of was up to 1000 $\mathrm{MPa}$ and the detailed mechanical properties is described in Table 2.

Table 1. Chemical composition of Q\&P980.

\begin{tabular}{|c|c|c|c|c|c|c|}
\hline \multirow{2}{*}{ Element } & \multicolumn{6}{|c|}{ Main alloying additions in investigated material (wt. \%) } \\
\cline { 2 - 7 } & $\mathrm{C}$ & $\mathrm{Si}$ & $\mathrm{Mn}$ & $\mathrm{P}$ & $\mathrm{S}$ & $\mathrm{Al}$ \\
\hline Q\&P980 & 0.03 & 1.49 & 1.82 & 0.017 & 0.0043 & 0.046 \\
\hline
\end{tabular}

Table 2. Mechanical properties of Q\&P980.

\begin{tabular}{|c|c|c|c|}
\hline \multirow{2}{*}{ Type } & \multicolumn{3}{|c|}{ Main mechanical properties of Q\&P980 (wt. \%) } \\
\cline { 2 - 4 } & Yield strength (MPa) & Tensile strength (MPa) & $\begin{array}{c}\text { Elongation } \\
(\%)\end{array}$ \\
\hline Q\&P980 & 820 & 1001 & 20 \\
\hline
\end{tabular}

\subsection{Welding parameters and test method}

The welding parameter of Q\&P980 with thickness of 2 $\mathrm{mm}$ shown in Table 3. The welding current arranged with $5 \mathrm{kA}, 9 \mathrm{kA}$ and $13 \mathrm{kA}$ to obtain the different failure mode of spot welds in Q\&P980. The other welding parameters shown here referred to AWS D8.9M:2012. The resistance spot welding trials conducted with direct water-cooling of electrodes in accordance with ISO 5821:2009(E). Maximum cooling water intake temperature: $20{ }^{\circ} \mathrm{C}$ for each electrode and the cooling water quantity was at least $4 \mathrm{l} / \mathrm{min}$ for each electrode. The electrode made from the alloy $\mathrm{CuCr} 1 \mathrm{Zr}$ and the geometry specified by ISO5821. During the whole resistance spot welding process, the electrodes need to be aligned.
Table 3. Welding parameters applied in RSW process.

\begin{tabular}{|c|c|c|c|c|c|}
\hline \multirow{2}{*}{ Type } & \multicolumn{5}{|c|}{ Welding parameters of Q\&P980 } \\
\cline { 2 - 6 } & $\begin{array}{c}\text { Squeezing } \\
\text { time } \\
(\mathrm{ms})\end{array}$ & $\begin{array}{c}\text { Welding } \\
\text { time } \\
(\mathrm{ms})\end{array}$ & $\begin{array}{c}\text { Welding } \\
\text { current } \\
(\mathrm{kA})\end{array}$ & $\begin{array}{c}\text { Holding } \\
\text { time } \\
(\mathrm{ms})\end{array}$ & $\begin{array}{c}\text { Electrode } \\
\text { force }(\mathrm{kN})\end{array}$ \\
\hline Value & 1000 & 580 & $5 / 9 / 13$ & 100 & 6 \\
\hline
\end{tabular}

Hardness measurement applied to describe the microstructure difference in resistance spot welds. The "Z" typed detecting line is one third of thickness far from the sheet surface with the inflection point in the softening line of heat-affected zone (HAZ). The test was performed on the unetched samples with a load of 1.96 $\mathrm{N}$ applied during $10 \mathrm{~s}$. Besides, the corrosion solution was $4 \%$ nital for cross-section test to measure the nugget diameter and scanning electron microscope (SEM) test to characterize the microstructure of resistance spot welds. The SEM test performed with $20 \mathrm{KV}$ and the working distance was between $8 \mathrm{~mm}$ to $15 \mathrm{~mm}$.

\section{Results and discussion}

\subsection{Resistance spot welding of Q\&P980}

The nugget diameter characterized by optical microscopic with welding current of $5 \mathrm{kA}, 9 \mathrm{kA}$ and 13 kA was shown in Fig. 1. As described, the nugget diameter increased with the increment of welding current in the joints of $2.0 \mathrm{~mm}$ Q\&P980. The three replicates for the each welding current agreed well with each other and the consistency of the resistance spot welding of Q\&P980 was acceptable. The average value of nugget diameter was about $2.8 \mathrm{~mm}, 7.6 \mathrm{~mm}$ and $8.8 \mathrm{~mm}$ for the welding current of $5 \mathrm{kA}, 9 \mathrm{kA}$ and $13 \mathrm{kA}$, respectively.

The nugget diameter increased sharply when the welding current was smaller and the increasing rate would be slower or even be negative with higher welding current. When the welding current was smaller, the heat convection and heat conduction was smaller leading to the growth of nugget. With lager welding current, the nugget formation was restricted by the weldability of the base metal because the spatter would limit the formation of nugget. Thus, the increasing rate of nugget was larger when the welding current increased from $5 \mathrm{kA}$ to $9 \mathrm{kA}$.

The microstructure of spot welds was significant to determine the failure mode. The spot weld was composited with fusion zone (FZ), upper-critical zone (UCZ), subcritical zone (SCZ) and base metal (BM). The UCZ and SCZ were both belonged to heat-affected zone (HAZ) of spot welds. The microstructure of the four zones examined by SEM test described in Fig. 2. As shown, the microstructure of FZ and UCZ was both martensite. However, the martensite morphology of the two zones was quite different. Lath martensite occurred in the FZ and the coarse martensite existed in the UCZ. Furthermore, the subcritical zone was composited of ferrite and fine martensite and the base metal was consisted of martensite, ferrite and retained austenite. 
For fusion zone, the current passed through the assembly sheets to promote formation of molten poor in the interface between two sheets, and then lath martensite appears caused by rapid solidification rate. The retained austenite in the base metal would transform to martensite with higher temperature than solid-liquid transformation temperature. HAZ located between fusion zone and base metal, experienced high temperature gradient caused by residual Joule heat after going through fusion zone. The grain growth in the columnar crystal perpendicular to the welded sheets leading to the formation of coarse martensite formation in UCZ. As for SCZ, the existence of ferrite was due to the relatively lower temperature than was between Ac1 and Ac3 when comparted to that of UCZ. With the rapid cooling rate during resistance spot welding process, ferrite and retained martensite occurred in the SCZ.

Retain austenite transformed to martensite driven by mechanical force in RSW process. The transformation from soft phase to hard phase resulting in the heterogeneity microstructure and mechanical performance in spot-welds with the different transformation degree of retained austenite in base metal.
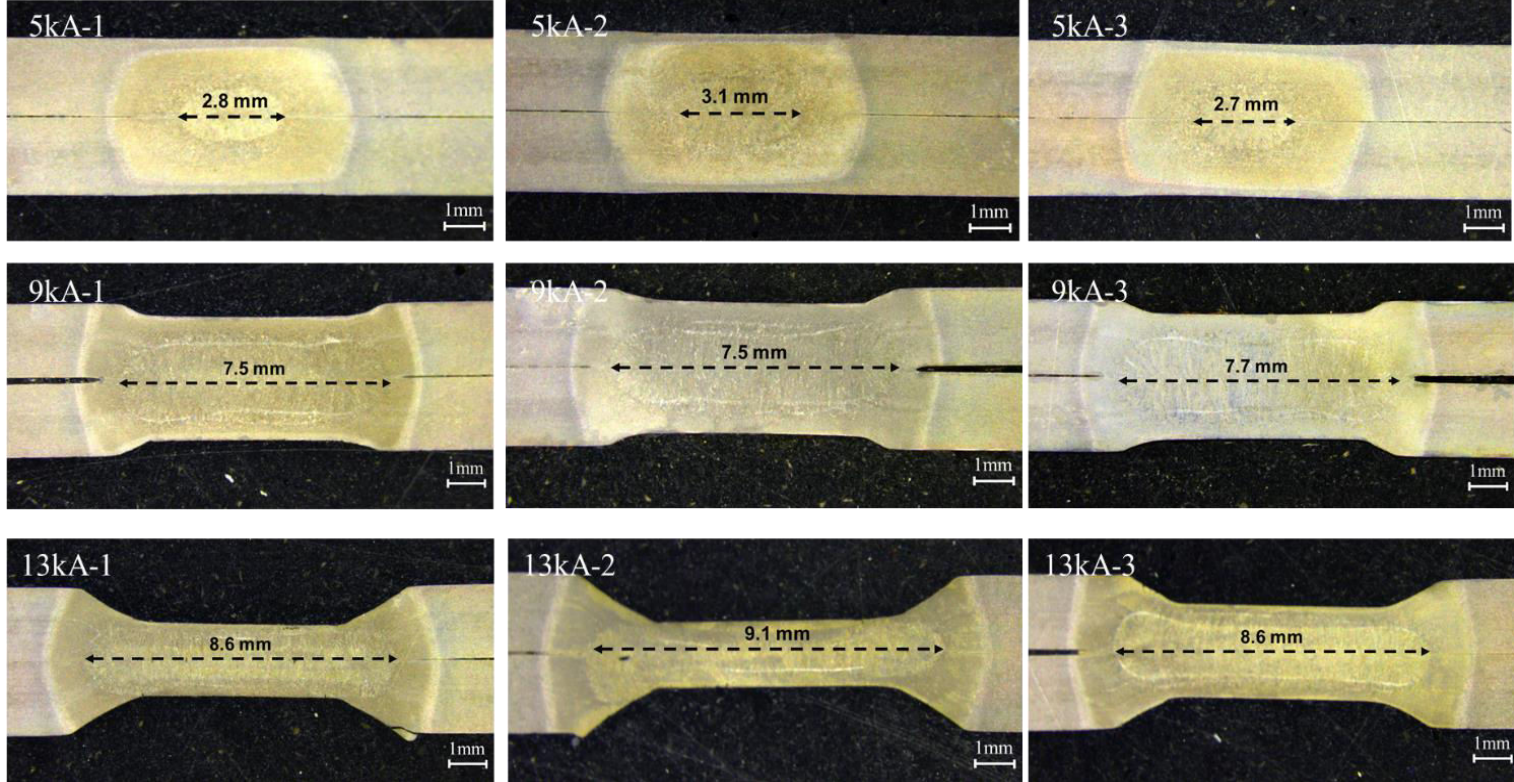

Fig. 1. The nugget diameter of resistance spot-welded Q\&P980 with welding current of $5 \mathrm{kA}, 9 \mathrm{kA}$ and $13 \mathrm{kA}$.
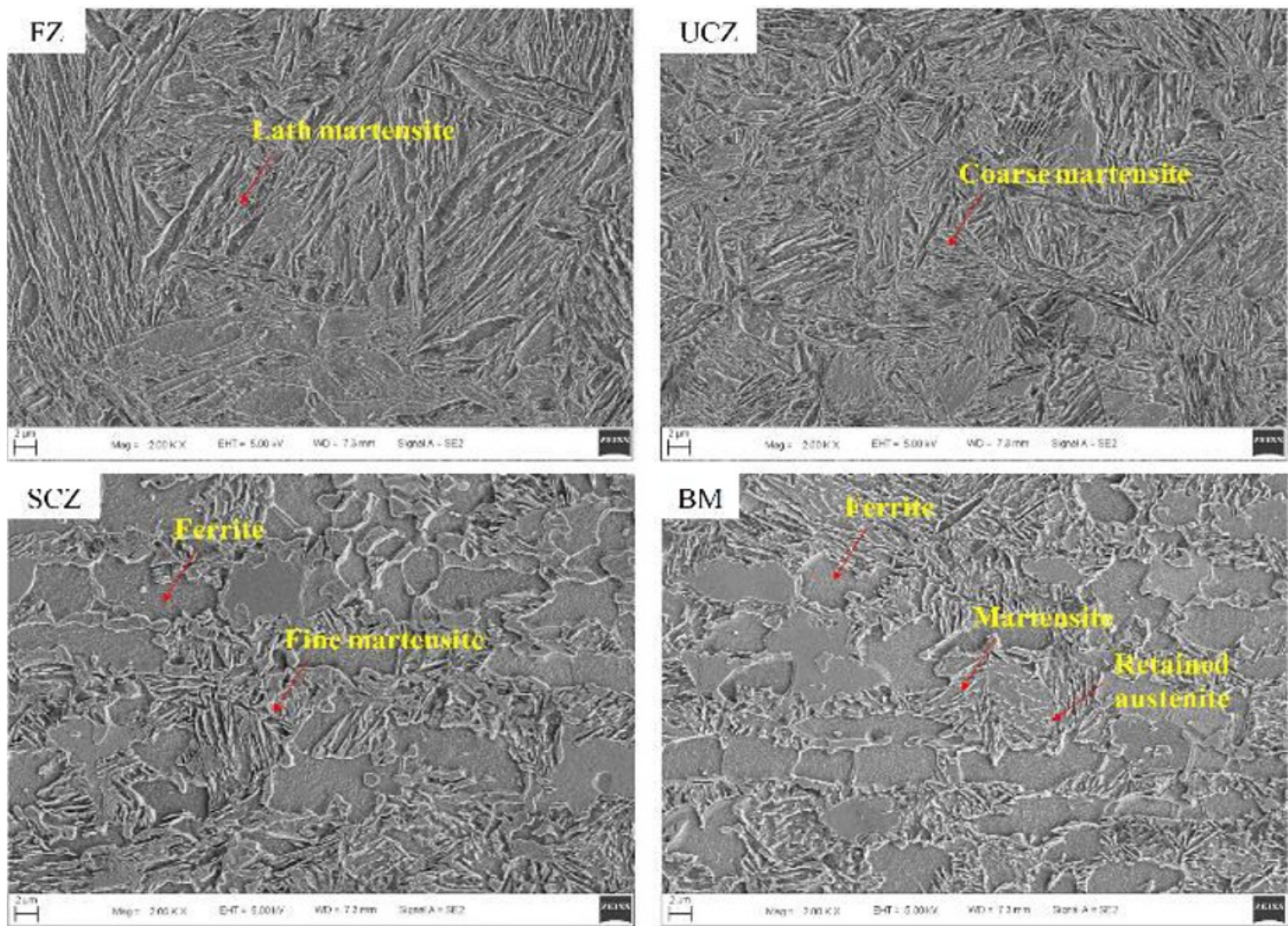

Fig. 2. Microstructure characterization of fusion zone (FZ), upper-critical zone (UCZ), subcritical zone (SCZ) and base metal (BM) in resistance spot-weld of Q\&P980. 
Hardness measurement was one of the methods to distinguish the difference of microstructure. The hardness value of FZ, UCZ, SCZ and BM depicted in Table 4, which was $524 \mathrm{Hv}, 509 \mathrm{Hv}, 396 \mathrm{Hv}$ and $330 \mathrm{Hv}$ respectively. The material soften occurred in the SZ, which was the same as other conventional advance high strength steel as like dual-phase steel. The hardness value of subcritical zone here was the average value among the whole zone.

The value of FZ, UCZ and SUZ was larger than BM in favour of the increased volume of fine martensite. The ferrite and retained austenite in the base metal of Q\&P980 would transformed to martensite during resistance spot welding process. Because the hardness of martensite was larger than that of ferrite and retained austenite, the transformation would increase the hardness property of microstructure and the effect would be larger with the processing of the transformation. Therefore, the hardness value of spot welds was larger than as-received Q\&P980 and the maximum hardness occurred in FZ due to the highest transformation degree of retained austenite.

Table 4. Hardness distribution of spot-welds.

\begin{tabular}{|c|c|c|c|c|}
\hline \multirow{2}{*}{ Zone } & \multicolumn{4}{|c|}{ Hardness distribution of resistance spot welded } \\
Q\&P980 \\
\cline { 2 - 5 } & Fusion zone & $\begin{array}{c}\text { Upper- } \\
\text { critical zone }\end{array}$ & $\begin{array}{c}\text { Subcritical } \\
\text { zone }\end{array}$ & Base metal \\
\hline Value (Hv) & 524 & 509 & 396 & 330 \\
\hline
\end{tabular}

To investigate the failure mode and validate the FEA model established in this paper, the quasi-static lap-shear tests was conducted with the welding current $5 \mathrm{kA}, 9 \mathrm{kA}$ and $13 \mathrm{kA}$ with three replicates and the results were shown in Fig. 3(a), Fig. 3(b) and Fig. 3(c), respectively.

As shown, the failure mode of $5 \mathrm{kA}$ and $9 \mathrm{kA}$ was both interfacial fracture. The crack initiation area was supposed to be in the major axis boundary of fusion zone due to the stress concentration according to the examination of fractured specimen shown in the Fig. 4. According to the force-displacement in Fig. 3(a) and Fig. 3(b), the maximum lap-shear force increased from about $11 \mathrm{kN}$ to $35 \mathrm{kN}$ with the increment of welding current from $5 \mathrm{kA}$ to $9 \mathrm{kA}$. The elongation of $9 \mathrm{kA}$ was about 4 times larger than that of $5 \mathrm{kA}$. Although the failure mode was both interfacial failure, the maximum force and energy absorption was increased with the increment of welding current.

The three replicates of force-displacement curves with welding current of $13 \mathrm{kA}$ demonstrated in Fig. 3(c). The failure mode of the three samples both included interfacial failure and partial interfacial failure according to the results shown in Fig. 4. Interfacial failure occurred in sample 1 and sample 2, the failure mode was partial interfacial failure in sample 3 as the fractured specimen shown in the right side. For partial interfacial failure, the nugget was partially damaged with the major part remained in the sheet. The fracture path was along the boundary of nugget and extended to the sheet surface.
Although the failure mode of the three samples were different, the maximum lap-shear force and elongation was similar. The welding current of $13 \mathrm{kA}$ might be the mixed zone where both interfacial failure and partial interfacial failure could both appear. Due to the serious spatter of $13 \mathrm{kA}$, the pullout failure might be hard to achieve in Q\&P980 with thickness of $2.0 \mathrm{~mm}$.

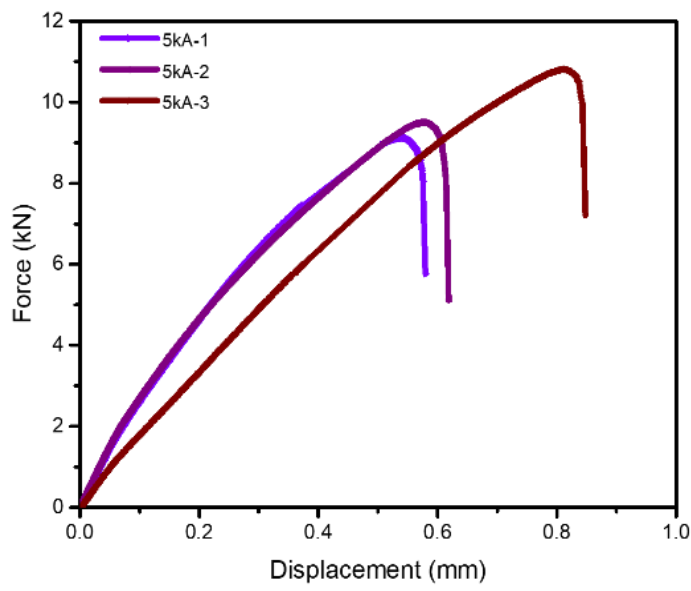

(a)

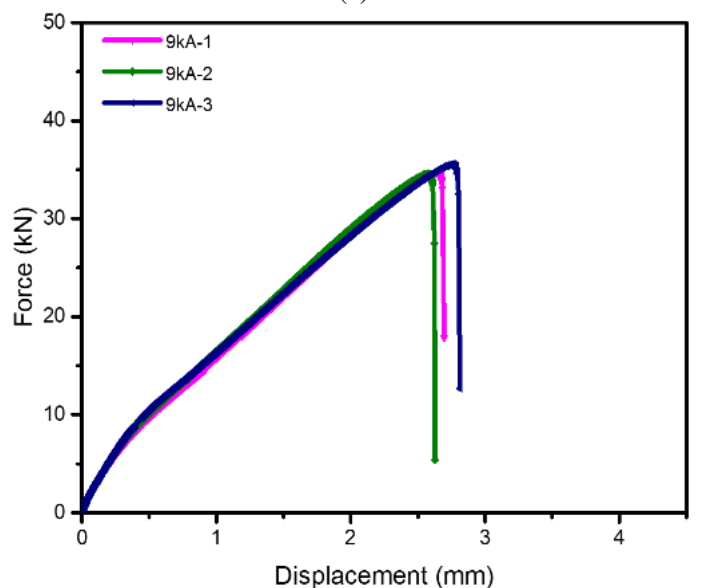

(b)

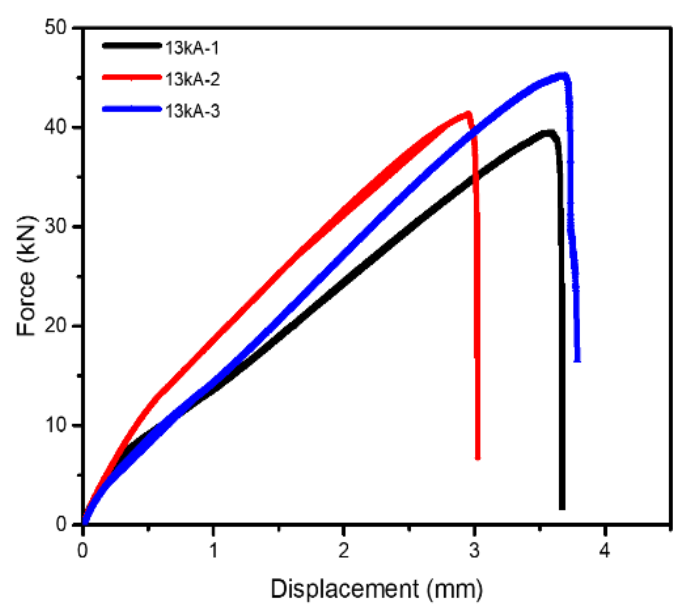

(c)

Fig. 3. Force-displacement curves of spot welds with welding current of (a) $5 \mathrm{kA}$, (b) $9 \mathrm{kA}$ and (c) $13 \mathrm{kA}$. 

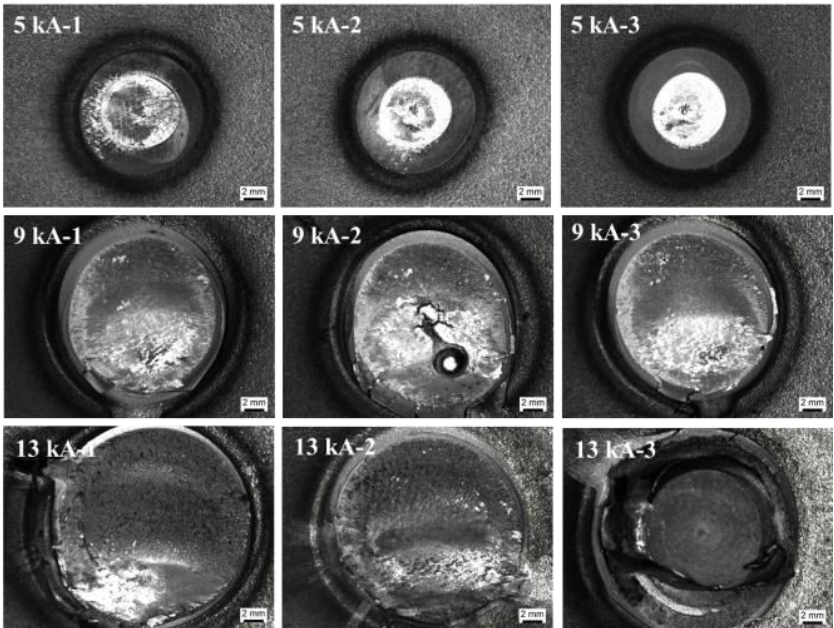

Fig. 4. Failure mode of spot-welds in $2.0 \mathrm{~mm}$ Q\&P980.

\subsection{Constitutive relationship}

The constitutive relationship played a significant role in failure mode determination of spot welds. The fedity of simulation largely depended on the accuracy of constitutive relationship of fusion zone. In order to the improve the measurement accuracy, a direct measurement method adopted DIC device had been used to obtain the stress-strain curve of fusion zone in this paper. The eometry of micro-specimen was 85 $\mathrm{mm} \times 17 \mathrm{~mm} \times 2.0 \mathrm{~mm}$ and the size extracted from the fusion zone was about $3 \mathrm{~mm} \times 3 \mathrm{~mm} \times 2.0 \mathrm{~mm}$. The small region in the fusion zone was to insure that failure occurs within the fusion zone and the large specimen was to provide convience to the experiments processing. Specimen preparation was illustrated in Fig. 5. Firstly, cut the profile of the specimen by wire electrical discharge machining (EDM) and then polished the specimen into the desired thickenss. Note that the specimen was without any treatment before experiments.

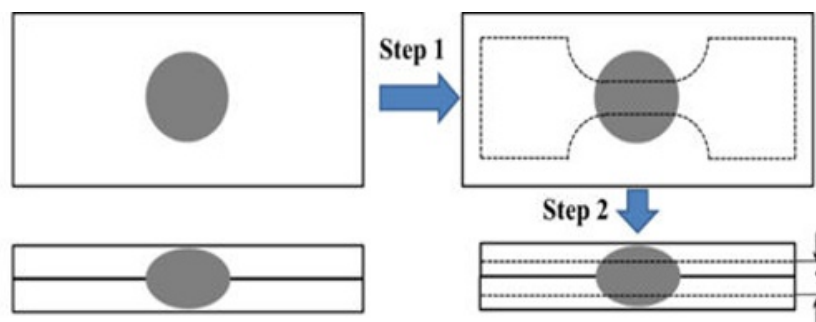

Fig. 5. The manufacturing process of specimen used for measuring the constitutive relationship of fusion zone in Q\&P980.

The constitutive relationship was acquired according to the engineering stress from tensile machine and the engineering strain from DIC device. The data matching was based on the data output frequency of tensile machine and the capturing increment of DIC device. The data from tensile machine every 2 seconds was corresponding to the strain calculated from obtained DIC captures in sequence. The strain rate in the experiments was intentionally fixed at $0.001 \mathrm{~s}-1$ to construct quasistatic test environment and three replicates are prepared for each test.

Figure. 6 depicted the experimental results of fusion zone in Q\&P980 with three replicates. As demonstrated, the experimental results was in favorable accordance in both ultimate tensile strength and elongation, which suggested that the consistency of the developed method was acceptable and the influence of EDM process could be neglected. Meanwhile, the yield strength of fusion zone in Q\&P980 was about $1000 \mathrm{MPa}$ and the ultimate tensile strength was up to $1600 \mathrm{MPa}$. Besides, the average elongation was about $25 \%$. Compared to the constitutive relation of as-received Q\&P980 demonstrated in Table 2, the ultimate tensile strength was enhanced due to the increase volume of martensite in fusion zone during RSW process. The elongation was about $32 \%$ with small tensile specimen, which was a little larger tan standard specimen based on ISO 6892 due to the effect of parallel length in specimen. To be concluded, the fusion zone performed better in ultimate tensile strength but the elongation was declined.

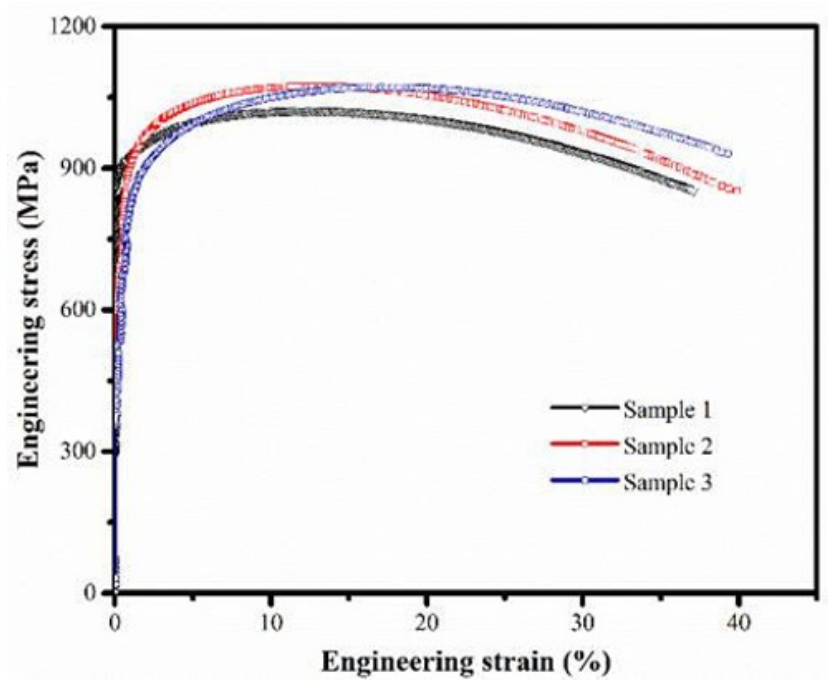

Fig. 6. Engineering stress-strain curves of fusion zone in spot welds of Q\&P980.

The extremely small size of the UCZ and SCZ made it hard to measure the constitutive relationship during tensile tests. Therefore, the constitutive relationship of the two zones was calculated according to the hardness extrapolation method. This method deducted the constitutive relationship based on the hardness distribution of spot welds and the constitutive relationship of base metal. Then constitutive relationship could be measured according to quasi-static tensile tests with standard specimen and the hardness distribution of spot welds in Q\&P980 shown in Table 4. Therefore, the constitutive relationship could be calculated and the results shown in Fig. 7. 


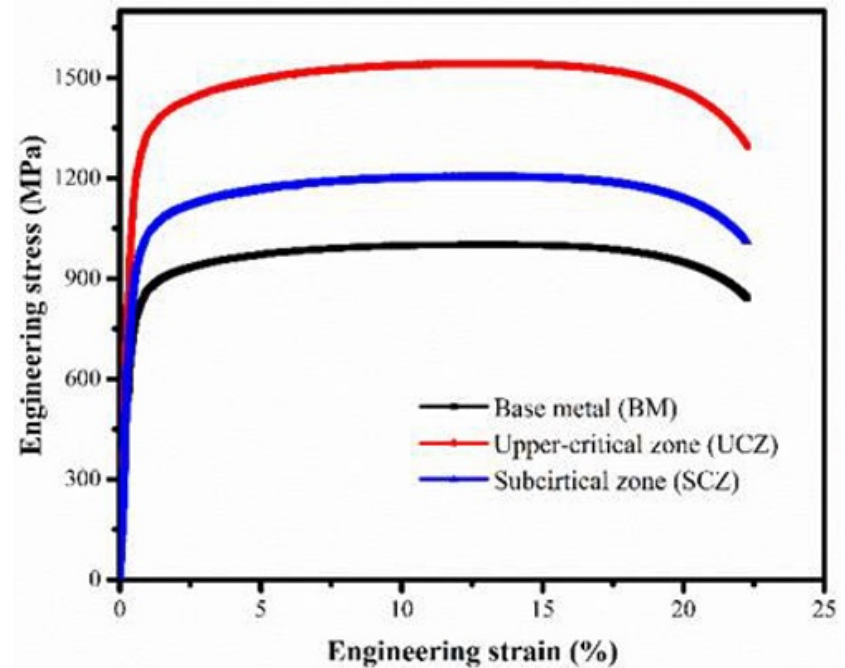

Fig. 7. True stress-strain curves of heat-affected zone in spot welds of Q\&P980.

\subsection{Validation}

Finite element model was developed using commercial FEA software Abaqus 6.14 to simulate the loaddisplacement response and failure mode of the specimen. To improve efficiency of simulation, tetrahedron element (C3D8R) was used for fusion zone and hexahedron element (C3D4) was used for heat-affected zone and base material. In total, there are 392,733 elements and 84,097 nodes in the FE model.

To simply the FE model and reduce simulation time, a half model had been considered due to symmetry of specimen. The coupon size of the model was 150 $\mathrm{mm} \times 50 \mathrm{~mm} \times 2.0 \mathrm{~mm}$. The gripping length and overlap length were $50 \mathrm{~mm}$ and $40 \mathrm{~mm}$, respectively. During the simulation, one specimen end was fixed and a displacement of $2 \mathrm{~mm} / \mathrm{min}$ was applied on the other, which was the same as crosshead speed in the quasistatic test.

The force-displacement curve was selected as the index to validate the developed FEA model. To validate the FEA mode with the failure mode of interfacial failure and partial interfacial failure, the validation would focus on the sample 2 of $5 \mathrm{kA}$ and sample 3 of $13 \mathrm{kA}$. The comparison results between simulation and experiments were shown in the following part.

The force-displacement curves of experiments and simulation when welding current was $5 \mathrm{kA}$ and the failure mode of experimental results were shown in Fig. 8. As shown, the failure area was across the nugget and the failure mode was determined as interfacial failure. As shown, the maximum force was about $9 \mathrm{kN}$ and the displacement was close to $0.6 \mathrm{~mm}$. The maximum force error between simulation result and experimental result was $1.2 \%$ for $5 \mathrm{kA}$ and the areas integrated by the two curves were almost the same. The force-displacement curve was extremely vital factor in mechanical properties evaluation criterion. The maximum force can evaluate the tensile strength and the energy absorption capability could be calculated by the integration of the curve. This result indicated that the simulation results agreed well with that of experiment results for forcedisplacement curve and the numerical model could be used to predict the force-displacement curve for interfacial failure.

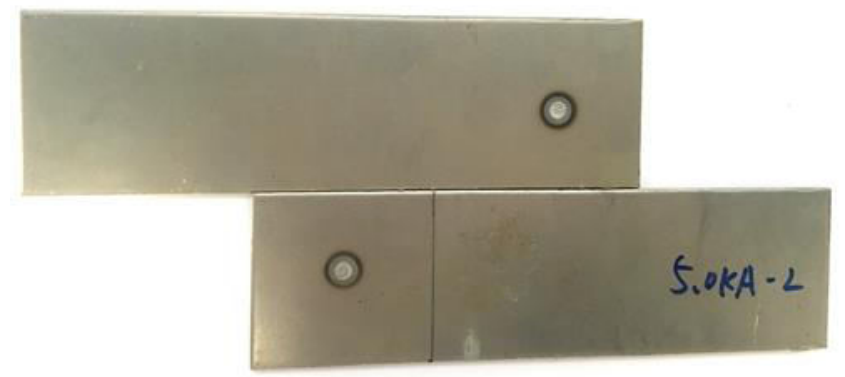

(a)

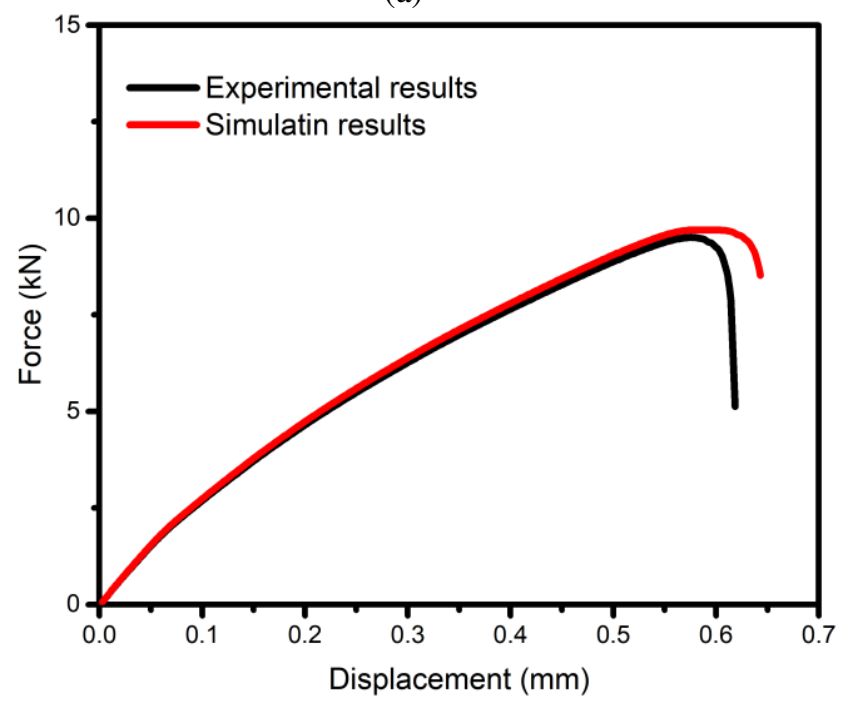

(b)

Fig. 8. (a)Failure mode of $5 \mathrm{kA}$, (b) Comparison of forcedisplacement curves by experiments and simulation with welding current of $5 \mathrm{kA}$.

The force-displacement curves of experiments and simulation with welding current was $13 \mathrm{kA}$ shown in Fig. 9. As shown, the fracture area was in the boundary of the fusion zone. The nugget zone damaged and partial of the fusion zone remained in the sheet. This kind of failure mode was determined as partial interface failure. According to the force-displacement curves, the maximum force was about $40 \mathrm{kN}$ and the displacement was close to $3.5 \mathrm{~mm}$. The maximum force error between simulation result and experimental result was $1.2 \%$ for $13 \mathrm{kA}$ and the areas integrated by the two curves were almost the same. This result indicated that the simulation results agreed well with that of experiment results for force-displacement curve and the numerical model could be used to predict the force-displacement curve for partial interfacial failure.

The fracture path of interfacial failure was across the nugget and that of partial interfacial failure extends from the boundary of fusion zone to the sheet surface. As for force-displacement curve, the maximum tensile force error was smaller than $2 \%$ for both interfacial failure and partial interfacial failure and the accuracy of the FEA model was acceptable. These results suggest that the numerical model performance well to investigate the mechanical properties for both interfacial failure and partial interfacial failure. 


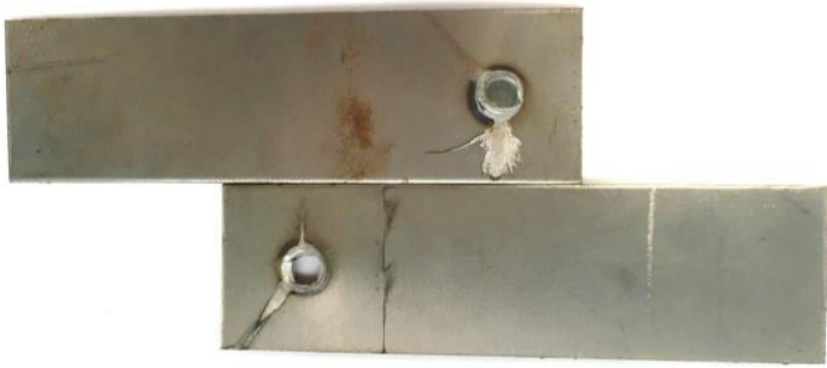

(a)

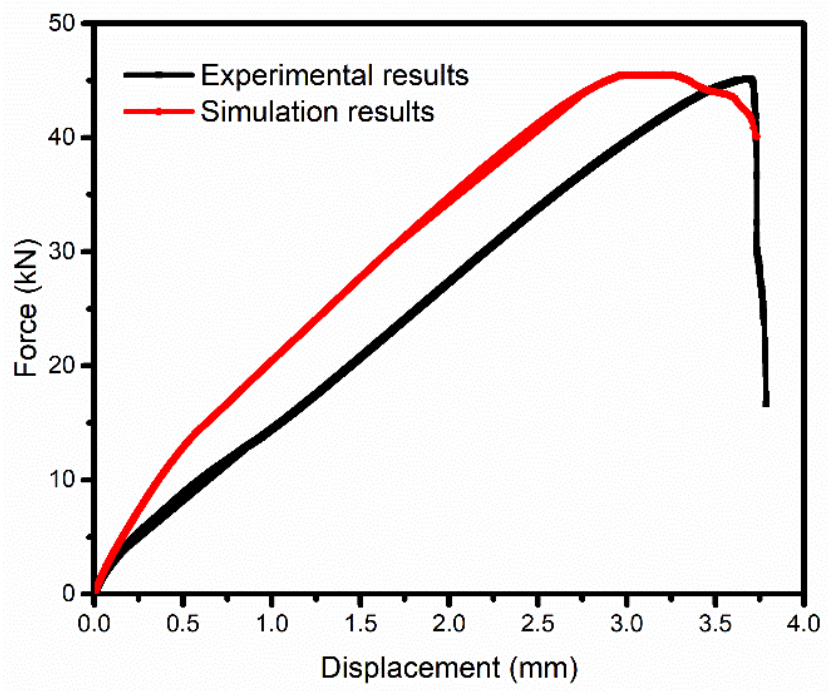

(b)

Fig. 9. (a) Failure mode and (b) force-displacement curves by experiments and simulation results with welding current of 13 $\mathrm{kA}$.

\section{Conclusion}

This paper established a FEA model to predict the failure mode of resistance spot-welded Q\&P980. The conclusion summarized as follows:

(1) A FEA model was setup for failure mode prediction of Q\&P980 and the simulation results agreed well with experimental results.

(2) An experimental setup equipped with DIC device was established to obtain the constitutive relationship of fusion zone in Q\&P980.

(3) Partial interfacial failure occurred with welding current of $13 \mathrm{kA}$ and the fracture area was around the boundary of fusion zone.

\section{References}

1. J. Speer, D.K. Matlock, B.C. De Cooman and J.G. Schroth, Acta. Mater. 51, 2611-2622 (2003)

2. X.H. Hu, X. Sun, L.G. Hector and Y. Ren, Acta. Mater. 132, 230-244 (2017)

3. C.M. Amodeo, W.J. Lai, J. Lee and J. Pan, Eng. Fract. Mech. 131, 74-99 (2014)

4. T. Huin, S. Dancette, D. Fabrègue and T. Dupuy, Metals. 6(5), 111 (2016)

5. K.L. Nielsen, In. J. Fracture. 153(2), 125-139 (2009)
6. Y.J. Chao, J Eng Mater Technol Trans ASME. 125(2), 125-132 (2003)

7. S.H. Lin, J. Pan, T. Tyan and P. Prasad, Int. J. Solids Struct. 40(21), 5539-5564 (2003)

8. S. Dancette, D. Fabregue, R. Estevez, V. Massardier, T. Dupuy and M. Bouzekri, Eng. Fract. Mech. 87, 48-61 (2012)

9. M. Pouranvari, S.P.H. Marashi and D.S. Safanama, Mater. Sci. Eng. A. 528(29-30), 8344-8352 (2011)

10. J. Wang, Y. Xia, Q. Zhou and J. Zhang, SAE Technical Papers, (2006)

11. R.J. Wang and D.G. Shang, Int. J. Fatigue 31, 508-514 (2009)

12. T.K. Eller, L. Greve, M.T. Andres, M. Medricky, A. Hatscher, V.T. Meinders and A.H. van den Boogaard, J. Mater. Process. Tech. 214, 1211-1227 (2015)

13. W. Tong, H. Tao, X. Jiang, N. Zhang, M.P. Marya, L.G. Hector Jr, and X.Q. Gayden, Metall. Mater. Trans. A. 36, 2651-2669 (2005)

14. N. Park, M. Park, J. Kwon and H. Huh, Sci. Technol. Weld. Joi. 23(1) 7-12 (2018.

15. H. Lee, C. Kim and J. Song, Materials. 8, 8424-8436 (2015)

16. K. Chung, W. Noh, X. Yang, H.N. Han and M. G. Lee, Int. J. Plasticity. 94, 122-147 (2017)

17. Z. Gronostajski, A. Niechajowicz, R. Kuziak, J. Krawczyk, and S. Polak, J. Mater. Process. Tech. 242, 246-259 (2017) 